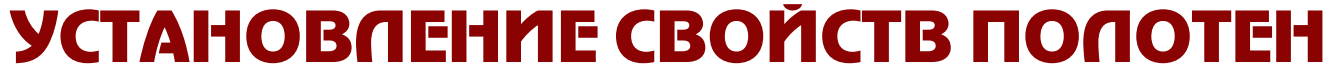 כПEKTPOחИत C BbICOKOCKOPOCTHЫM BOЗВРАTHO-ПОСТУПАTEПЫНЫЫM ПВИЖEHИEM ПOROTHA ПPИ

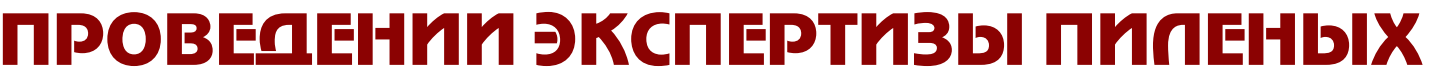 ПОВРЕЖАЕНИЙ КОЖИ
}

к.м.н. Ю.В. Назаров

Санкт-Петербургское государственное бюджетное учреждение здравоохранения «Бюро судебномедицинской экспертизы» (нач. - д.м.н. И.Е. Лобан), С-Петербург, кафедра судебной медицины (зав. - проф. Е. С. Мишин) Северо-Западного государственного медицинского университета им. И. И. Мечникова, С-Петербург

Аннотация:В ходе работы математически показана возможность определения свойств применённых пилок (полотен) электропил с высокоскоростным возвратно-поступательным движением полотна по выявленным морфологическим и размерным особенностям повреждений кожи человека. Полученные результаты показывают, что в случае судебно-медицинского исследования пиленых ран, причинённых электропилами с высокоскоростным возвратно-поступательным движением полотна, по морфологическим и размерным характеристикам повреждений можно достоверно утверждать, что пиление осуществлялось полотном с теми или иными конструкционными и размерными свойствами

Ключевые слова: пиленая рана, сабельная электропила, эксперимент, электролобзик

\section{DEFINITION OF THE PROPERTIES OF THE SAWBLADES WITH HIIGH SPEED POWER SAWS WITH TIHE RECIPROCATING MOVEMENT OF THE BLADE DURING THE EXAMINATION OF SAWN SKIN WOUNDS}

\section{Y. V. Nazarov}

Abstract: In the course of working mathematically shown the possibility of determining the properties of the applied saws (paintings) with high speed power saws of the reciprocating blade for morphological and dimensional characteristics of damage of human skin. The results show that in the case of forensic medical examination sawn wounds caused by power saws with high-speed reciprocating movement of cloth on morphological and dimensional characteristics of the claim that the sawing was carried out by painting with certain structural and dimensional properties.

Keywords: sawn wound, reciprocating electric saw, experiment, jigsaw

http://dx.doi.org/10.19048/2411-8729-2016-2-4-21-23

\section{$\checkmark$ ВВЕДЕНИЕ}

Исследование специальной литературы показывает, что накопленные практические и экспериментальные данные, посвящённые вопросам морфологических особенностей повреждений, относятся, в основном, к ручным пилам и не охватывают пилы, в которых возвратно-поступательное движение полотна осуществляется за счёт энергии электродвигателя.

На данный момент экспертиза повреждений, наносимых пилящими предметами, достаточно актуальна. Это обусловлено не только сравнительно высоким уровнем количества повреждений пилящими предметами, но и ростом в свободном обращении новых видов пилящих орудий и устройств. В экспертной практике всё чаще стали встречаться повреждения механическими пилящими устройствами, приводимыми в движение за счет преобразования энергии, получаемой от различных типов двигателей (электрического, внутреннего сгорания и т.п.), в частности - электропилами с высокоскоростным возвратно-поступательным движением полотна (электролобзиками и сабельными электропилами).
Остаются неизученными особенности повреждений кожных покровов человека электропилами с высокоскоростным возвратно-поступательным движением полотна, позволяющие определять основные характеристики применённых полотен.

Таким образом, целью данной работы явилось установление морфологических особенностей повреждений кожи человека, позволяющих установить основные характеристики применённых полотен в случаях нанесения ранений электропилами с высокоскоростным возвратнопоступательным движением полотна.

\section{$\checkmark$ МАТЕРИАЛЫ И МЕТОДЫ ИССЛЕДОВАНИЯ}

Для экспериментов применялись различные полотна (пилки) к электропилам с высокоскоростным возвратнопоступательным движением полотна (электролобзикам и сабельным электропилам).

Пиление осуществлялось с частотой движения пилки, равной 500 колебаний в минуту.

Объектами исследования явились 30 экспериментальных пиленых повреждений (по пять повреждений 


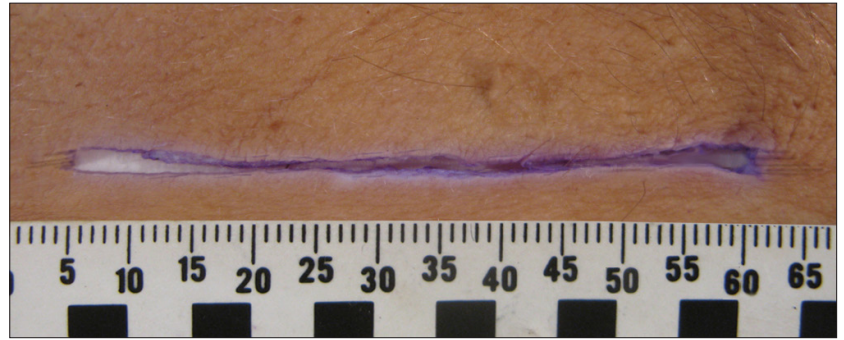

Рис. 1. Повреждение полотном с фрезерованными зубъями с простым наружным разводом с высотой зубиов 2,5 мм, шагом 4 мм, степенью развода 1,5 мм.

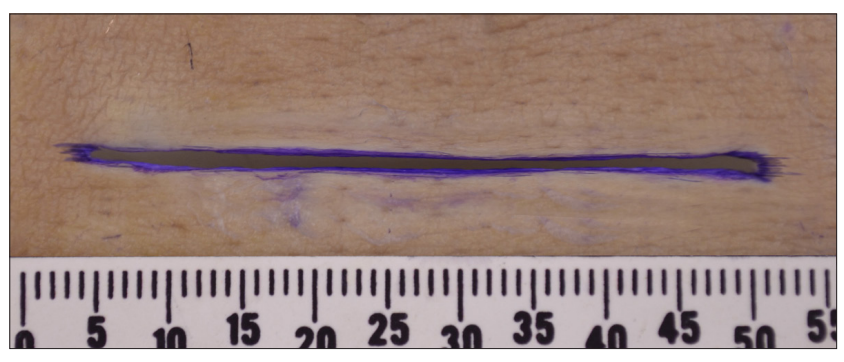

Рис. 2. Повреждение полотном с фрезерованными зубьями с простым наружным разводом с высотой зубцов 1,5 мМ, шагом 2 мм, степенью развода 1,5 мм.

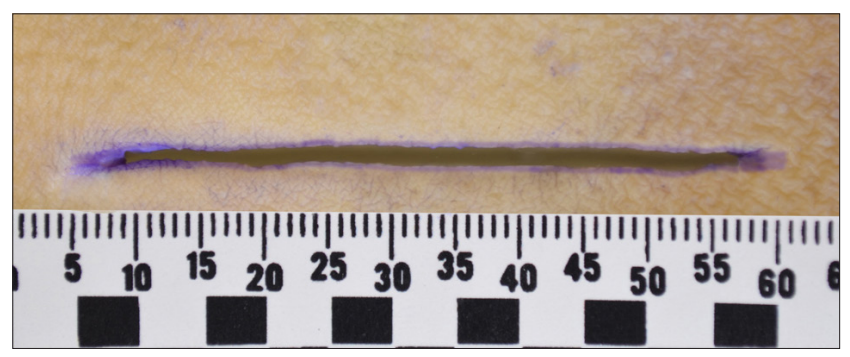

Рис. 3. Повреждение полотном с фрезерованными зубьями с волнистым разводом с выссотой зубиов 2,5 мм, шагом 4 мм, степенью развода 1,5 мм.

с каждой из шести выбранных пилок), проведённых поперёк выбранной конечности.

После нанесения ранений лоскуты кожи с повреждениями иссекались по сантиметровому шаблону и обрабатывались по способу А.Н. Ратневского (1972).

Полученные результаты экспериментов обрабатывали статистически.

Пиление области предплечья полотном с фрезерованными зубьями с простым наружным разводом с высотой зубцов 2,5 мм, шагом 4 мм, степенью развода 1,5 мм с частотой движения пилки 500 в мин. приводили к образованию ран линейной формы с неровными осаднёнными на ширину 1-2 мм. Вдоль краёв на расстоянии 3-5 мм друг от друга расположены множественные параллельные поверхностные надрезы. Стенки раны мелко неровные с многочисленными валиками и западениями. Концы ран П-образные шириной по 1,4-1,6 см с многочисленными переходящими в царапины поверхностными надрезами (рuс. 1).

Пиление области предплечья полотном с фрезерованными зубьями с простым наружным разводом с высотой зубцов 1,5 мм, шагом 2 мм, степенью развода 1,5 мм с частотой движения пилки 500 в мин. приводили к образованию ран линейной формы с неровными осаднёнными на ширину 1-2 мм краями. Вдоль краёв на расстоянии 1,5-2,5 мм друг от друга расположены

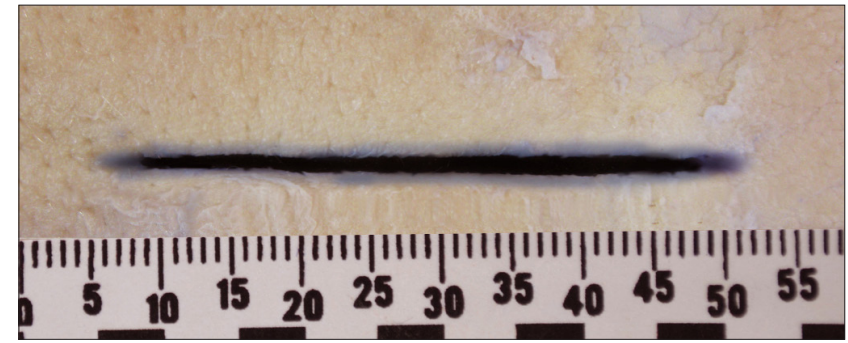

Рис. 4. Повреждение полотном с фрезерованными зубъями с волнистым разводом с высотой зубиов 1,5 мм, иагом 2 мм, степенью развода 1,5 мм.

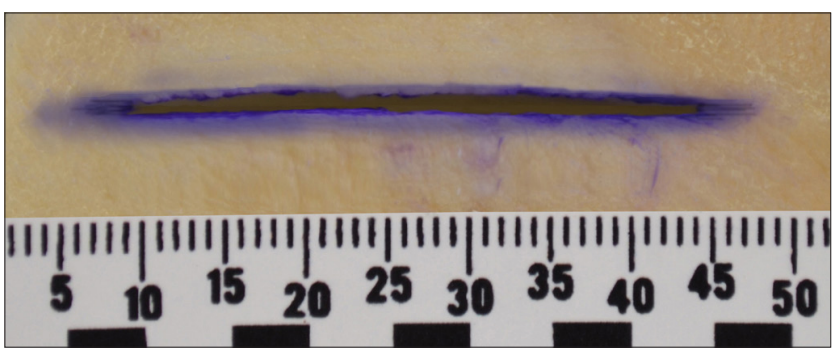

Рис. 5. Повреждение полотном со илифованными зубъями с простьм наружным разводом с высотой зубцов 2,5 мм, шагом 4 мм, степенью развода 1,5 мм.

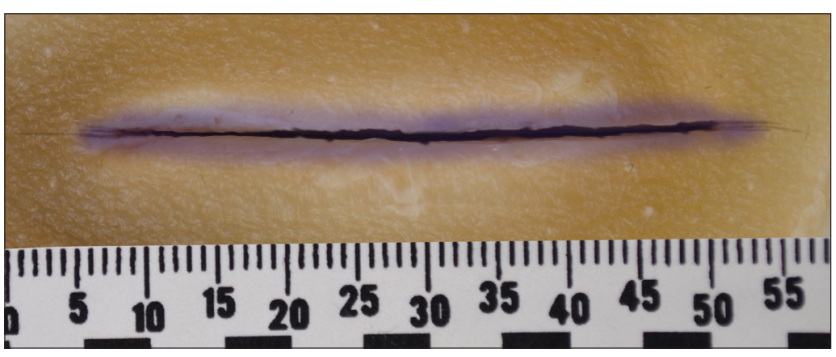

Рис. 6. Повреждение полотном со шлифованными зубьями с простым внутренним разводом с высотой зубцов 2 мм, шагом 3 мм, степенью развода 1,5 мм.

множественные параллельные поверхностные надрезы. Стенки раны мелко неровные с многочисленными валиками и западениями. Концы ран П-образные шириной по 1,4-1,6 см с многочисленными переходящими в царапины поверхностными надрезами (рuc. 2).

Пиление области предплечья полотном с фрезерованными зубьями с волнистым разводом с высотой зубцов 2,5 мм, шагом 4 мм, степенью развода 1,5 мм с частотой движения пилки 500 в мин. приводили к образованию ран линейной формы с неровными осаднёнными на ширину 0,5-1 мм краями. Стенки раны относительно ровные. Концы ран П-образные шириной по 1,4-1,6 см с многочисленными поверхностными надрезами, находящимися на расстоянии 3,5-4,5 мм друг от друга (рuс. 3).

Пиление области предплечья полотном с фрезерованными зубьями с волнистым разводом с высотой зубцов 1,5 мм, шагом 2 мм, степенью развода 1,5 мм с частотой движения пилки 500 в мин. приводили к образованию ран линейной формы с неровными осаднёнными на ширину 1-1,5 мм краями. Стенки раны относительно ровные. Концы ран П-образные шириной по 1,4-1,6 мм с многочисленными поверхностными надрезами, находящимися на расстоянии 1,5-2,5 мм друг от друга (рuс. 4).

Пиление области предплечья полотном со шлифованными зубьями с простым наружным разводом с высотой зубцов 2,5 мм, шагом 4 мм, степенью развода 
1,5 мм, с частотой движения пилки 500 в мин. приводили к образованию ран линейной формы с неровными осаднёнными на ширину 2,25-2,75 мм краями. Стенки раны относительно неровные. Концы ран М-образные шириной по 1,4-1,6 мм. Вдоль концов ран на расстоянии 3,5-4,5 мм друг от друга располагаются многочисленные поверхностные надрезы (рuс. 5).

Пиление области предплечья полотном со шлифованными зубьями с простым внутренним разводом с высотой зубцов 2 мм, шагом 3 мм, степенью развода 1,5 мм, с частотой движения пилки 500 в мин. приводили к образованию ран линейной формы с неровными осаднёнными на ширину 0,8-1,2 мм краями. Стенки раны относительно неровные. Концы ран М-образные шириной по 1,45-1,55 мм. В области концов ран на расстоянии 2,75-3,25 мм друг от друга располагаются многочисленные поверхностные надрезы (рис. 6).

С целью определения устойчивости и достоверности результатов экспериментальных исследований нами, кроме вариации признака по совокупности, определялось также количественное изменение признака, как по однородным группам совокупностей, так и между этими группами. В связи с вышесказанным, помимо общей средней для всей совокупности, просчитывались и частные средние величины по отдельным группам.

Для объективизирования полученных результатов нами применялся дисперсионный анализ, позволяющий вычислялись: общую, среднюю внутригрупповую и межгрупповую дисперсии.

Для вычисления общей дисперсии применялась формула: $\sigma_{0}^{2}=\left(\Sigma\left(X-\bar{X}_{0}\right)^{2} \cdot f\right) / \Sigma f$, где $\bar{X}_{0}-$ общая средняя арифметическая всей исследуемой совокупности. Средняя внутригрупповая дисперсия вычислялась двухэтапно: сначала рассчитывались дисперсии по отдельным группам $\sigma_{i}^{2}=\left(\Sigma\left(X-\bar{X}_{i}\right)^{2} \cdot f\right) / \Sigma f$, а затем - рассчитывалась средняя внутригрупповая дисперсия $\bar{\sigma}^{2}{ }_{i}=\left(\sum \sigma^{2}{ }_{i} \cdot n_{i}\right) /$ $\sum n_{i}$, где $n_{i}-$ число единиц в группе.

Дисперсия групповых средних (межгрупповая дисперсия) высчитывалась по формуле: $\sigma^{2}=\left(\Sigma\left(\bar{X}_{i}-\bar{X}_{0}\right)^{2}\right.$. $\left.n_{i}\right) / \sum n_{i}$ Где $X_{i}$ - средняя величина по отдельной группе.

После вычислений по вышеприведенным формулам находим: зависимость ширины осаднения раны от типа зубцов (шлифованные или фрезерованные), при этом общая дисперсия $\left(\sigma_{0}^{2}\right)=63,1$, средняя внутригрупповая дисперсия $\left(\bar{\sigma}^{2}{ }_{i}\right)=0,4$, межгрупповая дисперсия $\left(\sigma^{2}\right)=62,7$. Устанавливаем зависимость формы концов ран от вида развода (общая дисперсия $\left(\sigma_{0}^{2}\right)=60,4$; средняя внутригрупповая дисперсия $\left(\bar{\sigma}^{2}{ }_{i}\right)=$ 0,3 ; межгрупповая дисперсия $\left.\left(\sigma^{2}\right)=60,1\right)$. Вычисляем зависимость величин надрезов у краёв и концов ран от высоты зубцов, находя общую дисперсию $\left(\sigma^{2}\right)=$ 56,1, среднюю внутригрупповую дисперсию $\left(\bar{\sigma}^{2}{ }_{i}\right)=0,9$, межгрупповую дисперсию $\left(\sigma^{2}\right)=55,2$. Так же устанавливаем зависимость размера параллельных поверхностных надрезов вдоль краёв раны от шага зубцов полотна, при этом общая дисперсия $\left(\sigma^{2}\right)=58,5$, средняя внутригрупповая дисперсия $\left(\bar{\sigma}_{i}^{2}\right)=0,7$, межгрупповая дисперсия $\left.\left(\sigma^{2}\right)=57,8\right)$. Находим зависимость ширины концов ран от степени развода (общая дисперсия $\left(\sigma^{2}\right)=$ 69,4 ; средняя внутригрупповая дисперсия $\left(\bar{\sigma}^{2}{ }_{i}\right)=0,3$; межгрупповая дисперсия $\left.\left(\sigma^{2}\right)=69,1\right)$.

В ходе исследования расчет основного показателя силы влияния изучаемого признака проводили через показатель силы влияния $\left(\eta^{2}\right)$ факторного признака на результат, это определяется долей межгрупповой дисперсии $\left(\sigma^{2}\right)$ в общей дисперсии $\left(\sigma^{2}\right), \eta^{2}$ показывает, какую долю занимает влияние изучаемого фактора среди всех других факторов и устанавливается по формуле: $\eta^{2}=\left(\sigma^{2} / \sigma_{0}^{2}\right) \cdot 100 \%$.

Проводим расчёт для влияния типа зубцов на ширину осаднения: $\eta^{2}=(62,7 / 63,1) \cdot 100 \%=0,994 \cdot 100 \%=$ $99,4 \%$; влияние вида развода на форму концов раны: $\eta^{2}=(60,1 / 60,4) \cdot 100 \%=0,995 \cdot 100 \%=99,5 \%$; высоты зубцов на формирование величин надрезов у краёв и концов раны: $\eta^{2}=(55,2 / 56,1) \cdot 100 \%=0,984 \cdot 100 \%=$ $98,4 \%$; влияние шага зубцов полотна на размер параллельных поверхностных надрезов вдоль краёв раны: $\eta^{2}=(57,8 / 58,5) \cdot 100 \%=0,988 \cdot 100 \%=98,8 \%$; степени развода зубцов на ширину концов раны: $\eta^{2}=(69,1 /$ $69,4) \cdot 100 \%=0,996 \cdot 100 \%=99,6 \%$.

Следовательно, влияние различных конструкционных и размерных характеристик полотен (пилок) электропил с высокоскоростным возвратно-поступательным движением полотна на формирование морфологических свойств ран можно считать доказанным.

\section{$\diamond$ ВЫВоды}

Таким образом, полученные в экспериментах результаты показывают, что в случае судебно-медицинского исследования пиленых ран, причиненных электропилами с высокоскоростным возвратно-поступательным движением полотна, по морфологическим и размерным характеристикам повреждений можно достоверно утверждать, что пиление осуществлялось полотном с теми или иными конструкционными и размерными свойствами.

\section{Для корреспонденции:}

НАЗАРОВ Юрий Викторович - кандидат медицинских наук, заведующий медико-криминалистическим отделом Санкт-Петербургского государственного бюджетного учреждения здравоохранения «Бюро судебно-медицинской экспертизы», кафедра судебной медицины Северо-Западного государственного медицинского университета им. И. И. Мечникова $\div$ 195299, Санкт-Петербург, ул. Черкасова, д. 12, корп. 1, кв. 24. • naz532@yandex.ru •+7 (812) 54487-04 •

Конфликт интересов отсутствует. 